\title{
Climate of fear
}

\author{
The integrity of climate research has taken a very public battering in recent months. Scientists must now \\ emphasize the science, while acknowledging that they are in a street fight.
}

$\mathrm{C}$ limate scientists are on the defensive, knocked off balance by a re-energized community of global-warming deniers who, by dominating the media agenda, are sowing doubts about the fundamental science. Most researchers find themselves completely out of their league in this kind of battle because it's only superficially about the science. The real goal is to stoke the angry fires of talk radio, cable news, the blogosphere and the like, all of which feed off of contrarian story lines and seldom make the time to assess facts and weigh evidence. Civility, honesty, fact and perspective are irrelevant.

Worse, the onslaught seems to be working: some polls in the United States and abroad suggest that it is eroding public confidence in climate science at a time when the fundamental understanding of the climate system, although far from complete, is stronger than "Scientists must
not be so naive as to
assume that the data
speak for themselves."

Senator James Inhofe (Republican, Oklahoma), the leading climate sceptic in the US Congress, who labelled several respected climate scientists as potential criminals - nonsense that was hardly a surprise considering the source. Some scientists have responded by calling for a unified public rebuttal to Inhofe, and they have a point. As a member of the minority party, Inhofe is powerless for now, but that may one day change. In the meantime, Inhofe's report is only as effective as the attention it receives, which is why scientists need to be careful about how they engage such critics.

The core science supporting anthropogenic global warming has not changed. This needs to be stated again and again, in as many contexts as possible. Scientists must not be so naive as to assume that the data speak for themselves. Nor should governments. Scientific ever. Ecologist Paul Ehrlich at Stanford University in California says that his climate colleagues are at a loss about how to counter the attacks. "Everyone is scared shitless, but they don't know what to do," he says.

Researchers should not despair. For all the public's confusion about climate science, polls consistently show that people trust scientists more than almost anybody else to give honest advice. Yes, scientists' reputations have taken a hit thanks to headlines about the leaked climate e-mails at the University of East Anglia (UEA), UK, and an acknowledged mistake about the retreat of Himalayan glaciers in a recent report from the Intergovernmental Panel on Climate Change (IPCC). But these wounds are not necessarily fatal.

To make sure they are not, scientists must acknowledge that they are in a street fight, and that their relationship with the media really matters. Anything strategic that can be done on that front would be useful, be it media training for scientists or building links with credible public-relations firms. In this light, there are lessons to be learned from the current spate of controversies. For example, the IPCC error was originally caught by scientists, not sceptics. Had it been promptly corrected and openly explained to the media, in full context with the underlying science, the story would have lasted days, not weeks. The IPCC must establish a formal process for rapidly investigating and, when necessary, correcting such errors.

The unguarded exchanges in the UEA e-mails speak for themselves. Although the scientific process seems to have worked as it should have in the end, the e-mails do raise concerns about scientific behaviour and must be fully investigated. Public trust in scientists is based not just on their competence, but also on their perceived objectivity and openness. Researchers would be wise to remember this at all times, even when casually e-mailing colleagues.

US scientists recently learned this lesson yet again when a private e-mail discussion between leading climate researchers on how to deal with sceptics went live on conservative websites, leading to charges that the scientific elite was conspiring to silence climate sceptics (see page 149). The discussion was spurred by a report last month from agencies in the United States, Europe and beyond have been oddly silent over the recent controversies. In testimony on Capitol Hill last month, the head of the US Environmental Protection Agency, Lisa Jackson, offered at best a weak defence of the science while seeming to distance her agency's deliberations from a tarnished IPCC. Officials of her stature should be ready to defend scientists where necessary, and at all times give a credible explanation of the science.

These challenges are not new, and they won't go away any time soon. Even before the present controversies, climate legislation had hit a wall in the US Senate, where the poorly informed public debate often leaves one wondering whether science has any role at all. The IPCC's fourth assessment report had huge influence leading up to the climate conference in Copenhagen last year, but it was always clear that policymakers were reluctant to commit to serious reductions in greenhousegas emissions. Scientists can't do much about that, but they can and must continue to inform policy-makers about the underlying science and the potential consequences of policy decisions - while making sure they are not bested in the court of public opinion.

\section{Scientific glasnost}

\section{Russia's scientific reputation will continue to dwindle unless it embraces international research.}

\footnotetext{
- ver since the Soviet Union fell apart in 1991, Russian leaders - have been vowing to transform their old-line, industrial society - into a modern, knowledge-based economy driven by innovative science and technology. The current Russian president, Dmitry Medvedev, has repeated that ambition frequently - not least as a way to overcome Russia's dependence on oil and gas exports. Unfortunately, that transformation continues to be hobbled by outdated attitudes at the top of Russia's academic hierarchy.
} 